\title{
Pessoas vivendo com o vírus da imunodeficiência humana: percepção sobre atendimento odontológico
}

\section{People living with the human immunodeficiency virus: perception of dental care \\ Personas que viven con el virus de la inmunodeficiencia humana: percepción de la atención odontológica}

\author{
Brisa Ketrine Lustosa de Souza iD \\ Universidade Federal de Juiz de Fora - Governador Valadares - MG - Brasil
}

Ana Virgínia Fonseca Alves iD

Universidade Federal de Juiz de Fora - Governador Valadares - MG - Brasil

Lucas Eduardo Calheiros iD

Universidade Federal de Juiz de Fora - Governador Valadares - MG - Brasil

Waneska Alexandra Alves (D)

Universidade Federal de Juiz de Fora - Governador Valadares - MG - Brasil

Francielle Silvestre Verner (iD

Universidade Federal de Juiz de Fora - Governador Valadares - MG - Brasil

Sibele Nascimento de Aquino (iD

Universidade Federal de Juiz de Fora - Governador Valadares - MG - Brasil

\section{RESUMO}

Objetivo: Avaliar a percepção da pessoa vivendo com o vírus da imunodeficiência humana sobre a ocorrência de atitudes discriminatórias em atendimento odontológico. Métodos: Trata-se de um estudo qualitativo, realizado com pessoas vivendo com o vírus da imunodeficiência humana e em tratamento em um centro de referência, na cidade de Governador Valadares, Minas Gerais, Brasil, no período de janeiro a julho de 2019. Foram incluídos 25 participantes no estudo, tendo sido realizadas entrevistas semiestruturadas. Os dados coletados foram submetidos à análise de conteúdo temática e, a partir daí, as categorias que emergiram incluíram o receio da informação do diagnóstico ao profissional de saúde e a recusa de atendimento por profissionais da saúde. Resultados: Entre os entrevistados, houve percepção de confiança para informação de sua condição sorológica ao profissional, embora também tenha ocorrido omissão dela. Foi percebida certa insegurança relacionada ao cirurgião-dentista na realização do tratamento odontológico, incluindo atitudes discriminatórias no consultório e até recusa de atendimento. Conclusão: Entre as pessoas vivendo com o vírus da imunodeficiência humana investigadas no presente estudo, houve percepção de condutas discriminatórias e dificuldades para conseguirem atendimento odontológico, além do receio de informar seu diagnóstico ao cirurgião-dentista, omitindo-o.

Descritores: Sorodiagnóstico da AIDS; Odontologia; Discriminação Social.

\section{ABSTRACT}

Objective: To assess the perception people living with the human immunodeficiency virus have in relation to the occurrence of discriminatory attitudes during dental care. Methods: This is a qualitative study conducted with people living with the human immunodeficiency virus undergoing treatment in a reference center in the city of Governador Valadares, Minas Gerais, Brazil, from January to July 2019. The study included 25 participants, and semi-structured interviews were carried out. The collected data were subjected to Thematic Content Analysis and the categories that emerged included fear of disclosing the diagnosis to the health care professional and health care professionals' refusal to provide care. Results: Among the interviewees, there was a perception of trust in disclosing serological status to the professional, but there were also some who hid it. Certain insecurity was noted in dentists while delivering dental treatment, and there were some discriminatory attitudes in the office and even refusal to deliver care. Conclusion: There was a perception of discriminatory behavior and difficulties in obtaining dental care among the 
people living with the human immunodeficiency virus analyzed in the present study. In addition, there was fear of disclosing the diagnosis to the dentist, and some hid it.

Descriptors: AIDS Serodiagnosis; Dentistry; Social Discrimination.

\section{RESUMEN}

Objetivo: Evaluar la percepción de la persona que vive con el virus de la inmunodeficiencia humana sobre la ocurrencia de actitudes de discriminación durante la atención odontológica. Métodos: Se trata de un estudio cualitativo realizado con personas que viven con el virus de la inmunodeficiencia humana y en tratamiento en un centro de referencia de la ciudad de Governador Valadares, Minas Gerais, Brasil, en el periodo entre enero y julio de 2019. Se ha incluido 25 participantes en el estudio utilizándose de entrevistas semiestructuradas. Se ha realizado el análisis de contenido temático de los datos recogidos de los cuales emergieron las categorías que han incluido el miedo de la información del diagnóstico para el profesional sanitario y el rechazo de la atención de parte de los profesionales sanitarios. Resultados: Entre los entrevistados, hubo la percepción de confianza para dar la información de su condición serológica al profesional aunque también haya ocurrido la omisión de información. Se ha percibido cierta inseguridad relacionada al cirujano-odontólogo para la realización del tratamiento lo que incluye las actitudes de discriminación en el consultorio hasta el rechazo de la atención. Conclusión: Entre las personas que viven con el virus de la inmunodeficiencia humana investigadas en el estudio, hubo la percepción de conductas de discriminación y dificultades para conseguir la atención odontológica además del miedo para informar su diagnóstico al cirujano-odontólogo, omitiéndolo.

Descriptores: Serodiagnóstico del SIDA; Odontología; Discriminación Social.

\section{INTRODUÇÃO}

Com a evolução do conhecimento, a redução da mortalidade ocasionada pelo vírus da imunodeficiência humana (HIV) (do inglês Human Immunodeficiency Virus) tem aumentado substancialmente desde a sua identificação. Mais de 36 milhões de pessoas no mundo, atualmente, vivem com HIV, sendo a maioria em países subsaarianos ${ }^{(1)}$. No Brasil, entre 2007 e junho de 2018, foram notificados 300.496 casos de infecção pelo HIV e, desde o início da epidemia, na década de 1980, até junho de $2019,966,058$ pessoas foram identificadas ${ }^{(2)}$. A depleção de linfócitos TCD4 e a consequente imunossupressão, características da presença do HIV no organismo, tem sido extensivamente estudada, inclusive na população brasileira ${ }^{(3)}$.

Apesar do avanço do diagnóstico e da terapia antirretroviral terem alterado as características clínicas e epidemiológicas da doença e aumentado significativamente a expectativa de vida dos indivíduos em tratamento(4), as pessoas ainda podem sofrer com o preconceito e o estigma no convívio social e em ambientes de saúde. A discriminação na assistência à saúde pode ocorrer por meio de três configurações principais: a recusa de atendimento pelos profissionais após a revelação da condição sorológica, medidas extras de biossegurança ou por outras atitudes discriminatórias que incluem intervenções que não seriam indicadas a outros pacientes ${ }^{(5)}$.

O estigma é tido como um desfavor atribuído a uma pessoa com alguma diferença, sendo percebida como um defeito ou fraqueza, que a sociedade utiliza para desqualificá-la. Dessa forma, os estigmas de uma pessoa ou grupo podem provocar comportamentos como repulsa, distanciamento ou reações violentas ${ }^{(6)}$. A partir do surgimento da epidemia, construíram-se preconceitos relacionados à sexualidade e ao gênero das pessoas vivendo com o vírus da imunodeficiência humana (PVHIV) ${ }^{(7)}$.

No Brasil, a assistência à saúde possui respaldo legal, ético e biológico, mas ainda há indisposição de profissionais em prestar atendimento à pessoa soropositiva, sustentando atitudes discriminatórias ${ }^{(8)}$. A Política Nacional de Promoção da Saúde (PNPS) evidencia, no artigo $6^{\circ}$, a importância da promoção da equidade e da melhoria das condições e dos modos de viver, ampliando a potencialidade da saúde individual e da saúde coletiva e a redução das vulnerabilidades. Assim, salienta-se a importância das ações integradas e das intervenções nos determinantes sociais do processo de adoecimento( ${ }^{(9)}$.

Nesse sentido, destaca-se a importância da assistência integral à saúde entre PVHIV, incluindo a saúde bucal, devido a maior propensão às doenças oportunistas e à presença de manifestações orais, as quais podem ser os sinais iniciais da infecção pelo vírus da imunodeficiência humana (HIV). Algumas doenças, como a candidose oral, a leucoplasia pilosa oral, o sarcoma de Kaposi e o eritema linear gengival, além de sugerirem a infecção, podem indicar a progressão para a síndrome da imunodeficiência adquirida (AIDS). Ainda, nesse grupo de pacientes, a frequência de doenças periodontais reforça a importância da atenção e assistência à saúde bucal(10). 
Diante desse contexto, questiona-se a percepção da pessoa vivendo com o vírus da imunodeficiência humana acerca da ocorrência de atitudes discriminatórias na assistência à saúde bucal. Assim, a partir de uma abordagem qualitativa, este estudo teve como objetivo avaliar a percepção da pessoa vivendo com o vírus da imunodeficiência humana sobre a ocorrência de atitudes discriminatórias em atendimento odontológico.

\section{MÉTODOS}

Estudo do tipo qualitativo( ${ }^{(11)}$ realizado no Centro de Referência em Atenção Especial à Saúde (Crase) localizado no município de Governador Valadares, Minas Gerais, Brasil, no período de janeiro a julho de 2019.

O Crase é um serviço de referência à PVHIV para a cidade de Governador Valadares e municípios vizinhos, na região leste de Minas Gerais, e realiza o acolhimento, o diagnóstico e o tratamento de PVHIV, com equipe multidisciplinar ${ }^{(12)}$. Assim, o público-alvo deste estudo foi composto por PVHIV em tratamento no referido centro, conforme comprovação a partir dos exames anexados aos prontuários médicos. Os participantes foram convidados à medida que compareciam ao serviço para atendimento, previamente agendado com a equipe multidisciplinar.

Os critérios de inclusão foram: ser paciente do Crase, estar em tratamento para HIV, possuir mais de 18 anos de idade, ter procurado atendimento odontológico após o diagnóstico. Os critérios de exclusão foram: pessoas sem o diagnóstico comprovado por exames de HIV no prontuário, com dificuldade de comunicação, que não aceitaram participar do estudo e que não procuraram atendimento odontológico após o diagnóstico. Duas pessoas se negaram a participar do estudo, sem justificar o motivo. A amostra foi encerrada por saturação(13), sendo composta por 25 participantes.

A coleta de dados ocorreu por meio de entrevista semiestruturada ${ }^{(11)}$. Esse tipo de entrevista possibilita maior liberdade, favorecendo a expansão das falas, garantindo melhor expressão. As informações foram colhidas em ambiente amistoso, confortável e reservado, com duração média da entrevista de 40 minutos, e ocorreram após a saída do consultório odontológico.

A realização da entrevista semiestruturada teve duas etapas. A primeira possuía as variáveis de identificação dos participantes (sexo, idade, escolaridade e grau de instrução). E a segunda, as perguntas abertas, direcionadas por um roteiro, o qual foi baseado em instrumento previamente publicado ${ }^{(14)}$ e adaptado para o presente estudo, relacionando-as ao objetivo do estudo, ou seja, se o paciente percebeu alguma atitude discriminatória ao ser atendido no serviço odontológico por ser portador do vírus HIV.

As entrevistas foram realizadas e gravadas com um gravador de áudio de aparelho telefônico iPhone 7 Plus. Os relatos foram posteriormente transcritos e analisados por meio da análise de conteúdo temática(15), que ocorreu em três fases. $\mathrm{Na} 1^{\text {a }}$ fase, realizou-se a pré-análise ou leitura flutuante, sendo o primeiro contato com os documentos para analisar e conhecer os áudios, realizando-se, em seguida, a preparação do material, com as transcrições das entrevistas. $\mathrm{Na} 2^{\mathrm{a}}$ fase, realizou-se a exploração do material e sua codificação. Extraíram-se os elementos de registro, os núcleos de sentido, os elementos de contexto e, por fim, as categorias temáticas. Já na $3^{\text {a }}$ fase, ocorreu o tratamento dos resultados, de maneira a serem significantes e válidos. As seguintes categorias emergiram: "Receio de informar o diagnóstico ao profissional de saúde" e "A recusa de atendimento por profissionais da saúde".

Este estudo foi conduzido de acordo com as Resoluções n. ${ }^{\circ}$ 466/2012 e 510/2016 do Conselho Nacional de Saúde. Está contemplado em projeto aprovado pelo Comitê de Ética da Universidade Federal de Juiz de Fora (Parecer . $^{\circ}$ 1.821.072). Os participantes que concordaram em participar do estudo assinaram Termo de Consentimento Livre e Esclarecido. Os participantes tiveram o nome codificado por $\mathrm{P}$ (paciente) e foram enumerados de 1 a 25 , de acordo com a ordem das entrevistas. Suas informações pessoais foram preservadas aos cuidados exclusivos do entrevistador.

\section{RESULTADOS E DISCUSSÃO}

Os participantes deste estudo possuíam idade entre 35 e 65 anos, sendo compostos por homens e mulheres. Exceto por um participante sem escolaridade, os demais eram alfabetizados, sendo a menor escolaridade o ensino fundamental incompleto e a maior, o ensino superior completo.

A seguir, serão apresentadas as categorias "Receio de informar o diagnóstico ao profissional de saúde" e "A recusa de atendimento por profissionais da saúde".

\section{Receio de informar o diagnóstico ao profissional de saúde}

Nesta categoria, quanto ao receio de informar o diagnóstico ao profissional de saúde, por ser o local uma unidade de referência para PVHIV, os participantes relataram não ser necessário. Contudo alguns esclareceram que revelaram somente para o cirurgião-dentista de sua confiança: 
"Na época, informei somente a uma, a única dentista que eu era paciente dela. Eu confiava bastante nela. Inclusive, acho que até a atendente dela não sabia. Mas hoje, sinceramente, está difícil confiar nessas pessoas que eles estão colocando nos postos de saúde. Não é porque eles não aprendem na escola a ética profissional, não, mas eu acredito que hoje acham tudo normal, tudo natural. Mas, para quem tem isso, aí é diferente, eu não tenho preconceito e nem nada, mas eu ainda não acho normal ficar falando em ambiente que não é adequado." (P1)

Conforme o relato descrito anteriormente, o participante sentiu confiança para falar sobre a sua condição sorológica apenas para a cirurgiã-dentista da sua confiança. Essa conduta pode sugerir que, em algum momento, outros profissionais não transmitiram confiança. $\mathrm{O}$ artigo $5^{\circ}$ do Código de Ética Odontológica ${ }^{(16)}$ estabelece que o profissional deve guardar sigilo a respeito das informações adquiridas no desempenho de suas funções. Assim, o profissional que age diferente do que estabelece a legislação, além de cometer infração ética, também compromete a relação de confiança entre o paciente e o profissional, limitando, por vezes, o acompanhamento ideal desse paciente e causando estigmatização.

No relato a seguir, uma paciente disse ter coragem de informar sobre o seu diagnóstico. Então, observa ações extras de biossegurança durante procedimentos odontológicos, como pode ser visto na seguinte fala:

"Sempre quando eu falo, eles colocam umas duas luvas. Mas eu concordo, acho que é normal." (P7)

A biossegurança excessiva descrita pela paciente pode ser indício de discriminação. Apesar da participante do presente estudo não ter interpretado como ato discriminatório, outro estudo apontou que os participantes interpretaram o excesso de proteção por parte do profissional como discriminação(17).

Em outro relato, e de forma similar, após informar sobre o diagnóstico, o atendimento foi realizado com ações extras de biossegurança, como o uso de mais pares de luvas pelo profissional cirurgião-dentista, o que pode demonstrar despreparo e insegurança no atendimento quando o paciente informa seu diagnóstico de HIV. Nesse sentido, é possível sugerir que, mesmo com o avanço do conhecimento sobre o HIVIAIDS, há pessoas soropositivas com pouca informação sobre o que é um atendimento normal e padrão para qualquer ser social.

Em outras situações, os entrevistados do atual estudo não relataram sobre o seu diagnóstico desde o início da consulta, revelando somente na hora do procedimento, percebendo, em seguida, insegurança por parte dos profissionais, que aparentaram estar assustados, despreparados. Houve relato de profissional apresentando, inclusive, mudança de postura com o paciente, informando-o que deveria ter relatado suas condições de saúde durante a anamnese, previamente ao procedimento clínico. Sobre esse assunto, pode ser visto, a seguir:

"Ele ficou mais resguardado só. Quando eu pensei no sangramento na hora de tirar o dente, eu logo quis contar, por que vai que acontece alguma coisa com ele? Não sei, não é?! Aí eu falei, aí ele deu "tipo uma bronca", dizendo que eu devia ter dito antes. Ficou mais receoso. Eu falei no último minuto, acho que eu devia ter falado antes." (P10)

Esse comportamento do participante pode estar associado à experiência prévia de preconceito vivenciado, o que pode levá-lo a omitir o diagnóstico como defesa. Interessante destacar que um estudo apontou que mais da metade dos participantes omitiu sobre a sua condição sorológica para o cirurgião-dentista na anamnese ${ }^{(17)}$, talvez por ter o mesmo pensamento do P10.

Esse mecanismo de defesa pode comprometer a qualidade do atendimento prestado, pois o desconhecimento pelo cirurgião-dentista da real condição do paciente pode gerar um tratamento fragmentado e inadequado. Por outro lado, espera-se que o profissional não considere o diagnóstico de HIV como um sinal para exclusão do paciente ou necessidade de medidas adicionais de proteção individual. Nesse sentido, é considerado ideal que os cirurgiões-dentistas adotem uma postura igualitária, considerando todos os pacientes como potencialmente infectados, utilizando rotineiramente medidas de segurança iguais para todos ${ }^{(18)}$.

Destaca-se, ainda, que o risco de contaminação de cirurgiões-dentistas pelo HIV é extremamente baixo em comparação com outras doenças ${ }^{(19)}$, e, embora o risco de contaminação seja mínimo, esse profissional, por estar em contato com os fluidos que podem conter vírus, como o sangue e a saliva, está mais sujeito à contaminação.

Outro ponto a ser destacado é que alguns entrevistados informaram viver com o vírus HIV, mesmo que não compreendam a importância dessa informação para os profissionais de saúde que os atenderão:

"Ah, eu sou obrigado a informar ao "dentista", é?"(P6) 
O estigma, atrelado à ideia de que os indivíduos que vivem com HIVIAIDS são oriundos de populações marginalizadas, homossexuais, que vivem em promiscuidade sexual ou usam drogas, pode influenciar negativamente a disposição de profissionais de saúde para o atendimento ${ }^{(20)}$. Além da estigmatização, outro fator que se destaca é o medo da contaminação decorrente do pouco conhecimento sobre a transmissão do HIV, tanto em ambiente médico quanto odontológico ${ }^{21,22)}$. Interessante observar que, entre os diferentes profissionais de saúde incluídos em um estudo, níveis mais baixos de conhecimento sobre HIVIAIDS foram associados a níveis mais altos de atitudes estigmatizantes em relação às PVHIV(22).

Os relatos apresentados no atual estudo são coerentes com a literatura quanto à avaliação da atitude dos profissionais e estudantes de Odontologia( ${ }^{(23-25)}$. Um estudo avaliou as atitudes de estudantes de Odontologia em relação ao atendimento a PVHIV e observou que $92 \%$ dos estudantes eram relutantes para o tratamento ao paciente e que a discriminação foi alta ( $87 \%$ ). Entre os estudantes relutantes, a maioria apresentou uma tendência negativa em relação aos pacientes ${ }^{(24)}$. Outro estudo, realizado na China, com estudantes e cirurgiões-dentistas, apontou que há um baixo conforto ou vontade de atendimento a pacientes soropositivos, sendo que apenas $25 \%$ dos cirurgiões-dentistas apresentavam atitudes positivas para tratar a PVHIV. Esses dados indicam que há necessidade na graduação de mais informações, exercícios e discussões em grupo para reduzir o estigma e melhorar as atitudes ${ }^{(25,26)}$, destacando que, para o atendimento odontológico, a melhor conduta é adotar os procedimentos de biossegurança como rotina em qualquer atendimento, indiscriminadamente ${ }^{(27)}$.

\section{A recusa de atendimento por profissionais da saúde}

Esta categoria retrata a recusa de atendimento por profissionais da saúde, identificada nas falas dos entrevistados. Trata-se de uma forma de discriminação que se manifesta, muitas vezes, interrompendo o procedimento a partir do momento que o paciente revela viver com HIV. Esse fato pode ser evidenciado pela fala a seguir:

“(...) teve o maior preconceito. Quando eu falei com ele, ele simplesmente parou o que estava fazendo. Começou o atendimento e eu falei. Na hora, ele parou o que estava fazendo, só que aí ele só colocou o curativo, porque era obrigado a colocar, resumindo. Teve o maior preconceito. Só colocou e depois combinou de tirar e continuar o tratamento, mas quando eu voltei, nem tirar, tirou." (P14)

Há relato de consultas serem adiadas inúmeras vezes, sem uma explicação, até a desistência do atendimento:

"Fui várias vezes ao posto e sempre falavam a mesma coisa, colocavam a culpa na pressão ou em outra coisa, mas nunca podia atender. Marcava daqui a vinte dias, dava o dia e aumentava mais uns dez dias, voltava e não podia. Sempre era a mesma desculpa." (P3)

Houve, ainda, situação em que o cirurgião-dentista recusou o atendimento, alegando que o procedimento deveria ser feito no âmbito particular, devido a questões estruturais:

"Quando eu voltei ele disse: - Não, infelizmente o seu caso não é para mim, não, tem que ser um "dentista" particular. Eu fui a um "dentista" de postinho, ele me atendeu a primeira vez, porque não tinha como recusar. Falei perto de mais pessoas." (P5)

Houve ainda situações em que o entrevistado informou sobre o diagnóstico para um cirurgião-dentista do serviço público de saúde, propôs pagar pelo tratamento e o profissional recusou o atendimento:

"Os "dentistas" da minha cidade não gostam de me atender. A "dentista" olhou tudo e não quis fazer nada, mesmo que eu pagasse o canal de duas vezes, ela não quis fazer. Mas não por isso, eu vou processar ela, que Deus tome conta dela. Não é qualquer pessoa que gosta de atender gente tipo eu, não." (P22)

Há relato em que houve discriminação ao informar e optaram por não revelar mais:

“(...) Agora, eu já falo que, daqui para frente, eu não falo mais para ninguém que eu tenho esse problema quando for consultar, porque está tendo esse preconceito comigo. Eles que têm que se virar. Põe 7 luvas, 10 luvas." (P8)

A recusa de atendimento relatada mediante a informação da condição sorológica foi identificada nos participantes do atual estudo. Essa recusa pode refletir comportamentos discriminatórios do cirurgião-dentista. Interrupção durante o atendimento, agendamento e adiamento de consultas sem uma explicação coerente, e a orientação de que o tratamento só pode ser realizado no âmbito particular sugerem discriminação. Essas atitudes fazem com que as 
pessoas passem a esconder cada vez mais a sua situação sorológica, vivendo com grande estresse emocional, baixa autoestima e sentimento de culpa ${ }^{(28,29)}$, além de comprometer o tratamento integral do paciente. Deve-se salientar que os profissionais da saúde possuem a obrigação ética de fornecer atendimento confidencial a todos, sem julgamentos sobre sua identidade de gênero, orientação sexual, escolhas e comportamentos de vida, ou condição de saúde ${ }^{(30)}$.

O comportamento discriminatório pode ser fruto de deficiências na formação do profissional, em que há foco apenas na parte prática/técnica dos tratamentos odontológicos ${ }^{(31)}$, sem atenção ao tratamento integral e humanístico. Nesse sentido, a formação do cirurgião-dentista deve contemplar as necessidades sociais, bem como a integração ensino-serviço, e em consonância com as políticas nacionais de promoção de saúde. Uma formação humanizada e integralista pode ser um caminho para melhorar a conduta dos profissionais ${ }^{(32)}$.

Além do preconceito e do medo de contaminação, outra possível razão apontada como recusa de atendimento é o receio de perder clientes ou usuários do serviço por ficarem sabendo que o cirurgião-dentista específico faz o atendimento também para PVHIV ${ }^{(33)}$. No presente estudo, alguns entrevistados que apresentaram receio de ter o atendimento recusado ou um atendimento diferenciado não revelaram a sua condição sorológica. Uma revisão sistemática apontou que o estigma pode se manifestar por meio de comportamentos e ideologias, como homofobia, transfobia, racismo e opiniões negativas de pessoas que injetam drogas, e podem criar ambientes desconfortáveis e agir como uma barreira à prevenção, tratamento e cuidados com o $\mathrm{HIV}^{(8)}$.

O presente estudo evidenciou, ainda, atitudes discriminatórias do cirurgião-dentista no atendimento a PVHIV, seja por meio da recusa do atendimento ou pelo excesso de procedimentos de biossegurança, sendo resultados em consonância com a literatura ${ }^{(17,34)}$.

As atitudes discriminatórias realizadas por um profissional da saúde podem confrontar a Política Nacional de Saúde Pública (PNSP), a qual possui como objetivo a melhoria das condições de vida e a redução de vulnerabilidades e riscos à saúde decorrentes dos determinantes sociais, culturais e ambientais ${ }^{(9)}$. Destaca-se, ainda, a necessidade de regulamentação quanto ao acolhimento e atendimento a PVHIV, tanto nas políticas nacionais quanto para ambientes formativos em saúde.

Os dados do presente estudo apontam que, diante de situações discriminatórias, o paciente passa a deixar de informar o seu diagnóstico, passa a compreender como "normal" as medidas extras de biossegurança ou incorpora mais sofrimento na sua rotina após a recusa de atendimento, conforme mostrado nas falas dos participantes. Dessa forma, além da necessidade de inserção do tema nas políticas nacionais, deveria ocorrer estímulo a abordagens informativas, que abranjam a PVHIV e o atendimento de cirurgiões-dentistas.

Os profissionais de saúde podem se beneficiar com o treinamento em conjunto com PVHIV(35). Materiais educacionais e palestras informativas sobre formas de contaminação e transmissibilidade do HIV em serviços de saúde são essenciais. Ações que aumentem a conscientização e a sensibilidade dos profissionais de saúde podem ajudar a diminuir barreiras e estimular melhores resultados em PVHIV. É fundamental que o vínculo profissional-paciente seja mais humanizado e que os profissionais da saúde atuem de modo a reduzir o estigma, considerando que isso pode auxiliar na prevenção de novas infecções por HIV, além de aumentar o vínculo e a adesão ao tratamento como um todo ${ }^{(8)}$.

Os resultados do presente trabalho não podem ser generalizados, considerando-se a metodologia utilizada ${ }^{(36)}$. Entretanto, a postura relatada pelos entrevistados é reiterada pela literatura existente. Nesse sentido, podem ser usados para promover a educação social dos profissionais e estudantes da área de Odontologia, bem como para o norteamento de outros estudos relacionados à temática.

\section{CONCLUSÃO}

Este estudo indicou que, entre as pessoas vivendo com vírus da imunodeficiência humana investigadas, há o receio de informar seu diagnóstico ao cirurgião-dentista, omitindo-o, e que houve percepção da presença de atitudes discriminatórias por cirurgiões-dentistas, incluindo a recusa do atendimento e o uso excessivo de medidas de biossegurança.

O estudo sugere que há necessidade de maior capacitação e sensibilização dos cirurgiões-dentistas sobre a transmissão, a prevenção e o tratamento do HIV, bem como humanização do atendimento a pessoas vivendo com vírus da imunodeficiência humana.

\section{AGRADECIMENTOS}

Aos servidores do Centro de Referência em Atenção Especial à Saúde (Crase). 


\section{CONFLITOS DE INTERESSE}

Os autores declaram que não há conflito de interesses.

\section{CONTRIBUIÇÕES}

Sibele Nascimento de Aquino e Brisa Ketrine Lustosa de Souza contribuíram com a elaboração e delineamento do estudo, e com a redação/revisão do manuscrito. Ana Virgínia Fonseca Alves contribuiu com a aquisição dos dados e a redação/revisão do manuscrito. Lucas Eduardo Calheiros, Francielle Silvestre Verner, Waneska Alexandre Alves contribuíram com a análise e interpretação dos dados e a revisão do manuscrito.

\section{REFERÊNCIAS}

1. Adissu G, Biks GA, Tamirat KS. Patient satisfaction with antiretroviral therapy services and associated factors at Gondar town health centers, Northwest Ethiopia: an institution-based cross-sectional study. BMC Health Serv Res. 2020;20(1):93.

2. Ministério do Saúde (BR). Boletim Epidemiológico de HIV/Aids 2019 [Internet]. Brasília: Ministério da Saúde; 2019 [acesso em 2020 Set 13]. Disponível em: http://www.aids.gov.br/pt-br/pub/2019/boletim-epidemiologicode-hivaids-2019

3. Cassenote AJF, Granjeiro A, Escuder MM, Abe JM, Segurado AACS. Validation of CD4+ T-cell and viral load data from the HIV-Brazil Cohort Study using secondary system data. BMC Infec Dis. 2018;18(1):617.

4. Ghosn J, Taiwo B, Seedat S, Autran B, Katlama C. HIV. Lancet. 2018;392(10148):685-97.

5. Formozo GA, Oliveira DC. Auto-proteção profissional e cuidado de enfermagem ao paciente soropositivo ao HIV: duas facetas de uma representação. Acta Paul Enferm. 2009;22(4):392-8.

6. Goffman E. Estigma: notas sobre a manipulação da identidade deteriorada. Rio de Janeiro: Guanabara; 1988.

7. Juca MACL, Silva IAPD, Queiroga DEU, Carvalho AMAL, Ferreira SMS. Impacts of health of users with HIV/ AIDS in a specialized service. Rev Bras Enferm. 2019;72(6):1571-9.

8. Geter A, Herron AR, Suton MY. HIV-Related Stigma by Healthcare Providers in the United States: a systematic review. AIDS Patient Care STDs. 2018;32(10):418-24.

9. Ministério da Saúde (BR). Portaria No 2.446/GM de 11 de Novembro de 2014. Redefine a Política Nacional de Promoção da Saúde (PNPS). Brasília: Ministério da Saúde; 2014.

10. Howati AE, Tappuni A. Systematic review of the changing pattern of the oral manifestations of HIV. J Investig Clin Dent. 2018;9:e12351.

11. Godoy AS. Pesquisa qualitativa tipos fundamentais. Rev Adm Empres. 1995;359(3):20-9.

12. Ministério da Saúde (BR). Centro de referência em atenção especial à saúde ladislau salles-Crase [Internet]. Brasília: Ministério da Saúde; [2019] [acesso em 2020 Set 15]. Disponível em: http://www.aids.gov.br/pt-br/ centro-de-referencia-em-atencao-especial-saude-ladislau-salles-crase

13. Fontanella BJB, Luchesi BM, Saidel MGB, Ricas J, Turato ER, Melo DG. Amostragem em pesquisas qualitativas: proposta de procedimentos para constatar saturação teórica. Cad Saúde Pública. 2011;27(2):389-94.

14. Lelis RT, Soares GB, Garbin AJI, Garbin CAS. Discriminação vivenciada por pessoas que vivem com HIV/ AIDS nos serviços de saúde: um estudo qualitativo. Rev Cien Plural. 2016;2(3):17-29

15. Bardin L. Análise de conteúdo. São Paulo: Edições 70; 2011.

16. Brasil. Conselho Federal de Odontologia. Resolução CFO n 118, de 11 de maio de 2012. Revoga o Código de Ética Odontológica aprovado pela Resolução CFO 42/2003 e aprova outro em substituição. Diário Oficial da União: Seção 1, Brasília, DF, n. 114, p. 118, 14 jun 2012.

17. Muniz BAA, Fonte DCB, Santos SC. Percepção do portador de HIVIAIDS sobre o cirurgião-dentista. Rev Bioet. 2019;27(2):289-96. 
18. Centers for Disease Control and Prevention. Recommendations for prevention of HIV transmission in healthcare settings. Morb Mortal Wkly Rep. 1987;36(2):1S-18S.

19. Nwaiwu CA, Egro FM, Smith S, Harper JD, Spiess AM. Seroconversion rate among health care workers exposed to HIV-contaminated body fluids: the University of Pittsburgh 13-year experience. Am J Infect Control. 2017;45(8):896-900.

20. Villela WV, Monteiro S. Gênero, estigma e saúde: reflexões a partir da prostituição, do aborto e do HIVIAIDS entre mulheres. Epidemiol Serv Saúde. 2015;24(3);531-40.

21. Gagnon M. Re-thinking HIV-Related Stigma in Health Care Settings: a Qualitative Study. J Assoc Nurses AIDS Care. 2015;26(6):703-19.

22. Vorasane S, Jimba M, Kikuchi K, Yasuoka K, Durham J, Sychareun V. An investigation of stigmatizing attitudes towards people living with HIVIAIDS by doctors and nurses in Vientiniane, LAO PDR. BMC Health. Serv Res. 2017;17(1):125.

23. Premadasa G, Sadek M, Ellepola A, Sreedharan J, Muttappallymyalil J. Knowledge of and attitudes towards HIVIAIDS: a survey amongdental students in Ajman, UAE. J Investig Clin Dent. 2015;6(2):147-55.

24. Alshouibi E, Alaqil F. HIV-Related Discrimination among Senior Dental Students in Jeddah. J IntSocPrev Community Dent. 2019;9(3):219-24.

25. Lee C, Fan Y, Starr JR, Dogon IL. Dentists' and dental students' attitudes, knowledge, preparedness, and willingness related to treatment of people living with HIVIAIDS in China. J Public Health Dent. 2016;77(1):30-8.

26. Doda A, Negi G, Gaur DS, Harsh M. Human immunodeficiency virus/acquired immune deficiency syndrome: a survey on the knowledge, attitude, and practice among medical professionals at a tertiary health-care institution in Uttarakhand, India. Asian J Transfus Sci. 2018;12(1):21-6.

27. Lorosa AH, Pereira CM, Hussne RP, Silva-Boghossian CM. Evaluation of dental students' knowledge and patient care towards HIVIAIDS individuals. Eur J Dent Educ. 2019;23(2):212-9.

28. Giuliani M, Lajolo C, Rezza G, Arici C, Babudieri S, Grima P, et al. Dental care and HIV-infected individuals: are they equally treated? Community Dent Oral Epidemiol. 2005;33:447-53.

29. Frencha $\mathrm{H}$, Greeff M, Watsona M, Doakb CM. HIV stigma and disclosure experiences of people living with HIV in an urban and a rural setting. AIDS Care. 2015;27(8);1042-46.

30. The Lancet. HIV: Science and stigma. Lancet. 2014;384:207.

31. Parola G, Zilmann K. A saúde bucal na perspectiva das pessoas vivendo com HIVIAIDS: subsídios para a educação permanente de cirurgiões-dentistas. Interface. 2019;23:e180441.

32. Pinheiro FMC, Nóbrega-Therrien SM, Almeida MEL, Almeida MI. A formação do cirurgião-dentista no Brasil: contribuições de estudos para a prática da profissão. Rev Gaúcha Odontol. 2009;57(1):99-106.

33. Pagliari AV, Garbin AS, Garbin AJI. HIV attitudes and practices among professors in a Brazilian dental school. J Dent Educ. 2004;68:1278-83.

34. Discacciati JAC, Vilaça ÊL. Atendimento odontológico ao portador do HIV: medo, preconceito e ética profissional. Rev Panam Salud Pública. 2011;9(4):234-39.

35. Kalembio FW, Kendall GE, Ali M, Chimwaza AF, Tallon MM. Primary caregivers, healthcare workers, teachers and community leaders' perceptions and experiences of their involvement, practice and challenges of disclosure of HIV status to children living with HIV in Malawi: a qualitative study. BMC Public Health. 2018;18(1):884.

36. Sousa AJ. A generalização dos resultados da pesquisa qualitativa no campo da Administração: reflexão sobre seus limites e possibilidades. Braz J Develop. 2016;3:465-80. 
Endereço do primeiro autor:

Brisa Ketrine Lustosa de Souza

Universidade Federal de Juiz de Fora

Av. Raimundo Monteiro Rezende, 330

Bairro: Centro

CEP: 35010173 - Governador Valadares - MG - Brasil

E-mail: brisa.ketrine@hotmail.com

\section{Endereço para correspondência:}

Sibele Nascimento de Aquino

Universidade Federal de Juiz de Fora

Av. Raimundo Monteiro Rezende, 330

Bairro: Centro

CEP: 35010173 - Governador Valadares - MG - Brasil

E-mail: sibele.aquino@ufjf.edu.br

Como citar: Souza BKL, Alves AVF, Calheiros LE, Alves WA, Verner FS, Aquino SN. Pessoas vivendo com o vírus da imunodeficiência humana: percepção sobre atendimento odontológico. Rev Bras Promoç Saúde. 2021;34:10542. 